\title{
A SIMPLE FORMULA FOR ADJUSTING ARTERIAL CARBON DIOXIDE TENSION
}

\author{
H.R. WeXler AND PETER LoK
}

\begin{abstract}
To improve the accuracy of acid-base adjustment in mechanically ventilated patients we derived the formula:

Required minute ventilation $=\frac{\text { known arterial } \mathrm{PCO}_{2} \times \text { known minute ventilation }}{\text { desired arterial } \mathrm{PCO}_{2}}$

which allows calculation of the minute ventilation required to produce a desired arterial $\mathrm{PCO}_{2}$ by measuring the patient's existing arterial $\mathbf{P C O}_{2}$ and minute ventilation. This was tested in fifty patients using four types of ventilators and found to be statistically accurate, with a mean difference between predicted and observed $\mathrm{PCO}_{2}$ of $0.153 \mathrm{kPa}(1.15$ torr $) \pm$ S.E.M. 0.798.
\end{abstract}

Key Words: Acid-BASE Equilibrium, adjustment; Ventilation, mechanical, adjustment formula.

Mechanical ventilation to control arterial carbon dioxide tension may be indicated not only in patients with respiratory failure but also in situations where there is a need to manipulate the arterial $\mathrm{PCO}_{2}$ outside of the normal physiological range such as in patients with head injury. The desired arterial $\mathrm{PCO}_{2}$ is achieved by varying the minute ventilation of the patient and while there are rough guidelines related to body weight and surface area such as the Radford nomogram' which assists in the initial choice of minute ventilation, none of these take into account factors such as the dead space to tidal volume ratio or the minute carbon dioxide production of the patient. Therefore after an initial arterial blood gas has been measured, the patient's minute ventilation must often be increased or decreased to achieve the desired arterial $\mathrm{PCO}_{2}$ value, and a further blood gas measurement must be made. Several adjustments may be required, or a less than optimal value may be accepted as "close enough". We have derived a formula to improve the accuracy of acid-base adjustment in mechanically ventilated patients and evaluated its use in fifty patients using four types of ventilators.

H.R. Wexler, M.D., F.R.C.P.(C), Department of Anaesthesia; Peter Lok, R.R.T., Department of Respiratory Technology, University of Western Ontario, University Hospital, London, Ontario, Canada.

Address for reprints: Dr. H.R. Wexler, Department of Anaesthesia, University Hospital, P.O. Box 5339, Postal Stn. A., London, Canada. N6A 5A5.

\section{Derivation of Formula}

Since the inspired carbon dioxide is virtually zero,

$$
\mathrm{CA}_{\mathrm{CO}_{2}}=\frac{\dot{\mathrm{VCO}_{2}}}{\dot{\mathrm{V}}}
$$

$$
\begin{aligned}
\mathrm{CA}_{\mathrm{CO}_{2}}: \text { Alveolar Carbon Dioxide (per cent) } \\
\dot{\mathrm{V}}_{\mathrm{CO}_{2}}: \mathrm{CO}_{2} \text { production }(\mathrm{ml} / \mathrm{min}) \\
\dot{\mathrm{V}}_{\mathrm{A}}: \text { Alveolar ventilation }(\mathrm{ml} / \mathrm{min})
\end{aligned}
$$

Since the partial pressure of carbon dioxide in the alveolus $\left(\mathrm{PA}_{\mathrm{CO}_{2}}\right)$ is equal to the $\mathrm{CA}_{\mathrm{CO}_{2}} \times$ the dry ambient pressure $(\mathrm{PB})^{2}$

$$
\therefore \mathrm{PA}_{\mathrm{CO}_{2}}=\frac{\dot{\mathrm{V}}_{\mathrm{CO}_{2}}}{\dot{\mathrm{V}}_{\mathrm{A}}} \cdot \mathrm{PB}
$$

At equilibrium, the $\mathrm{PA}_{\mathrm{CO}_{2}}=\mathrm{P}_{\mathrm{CO}_{2}}$ in arterial blood $\left(\mathrm{Pa}_{\mathrm{CO}_{2}}\right)^{3}$

$$
\therefore \mathrm{Pa}_{\mathrm{CO}_{2}}=\frac{\dot{\mathrm{V}} \mathrm{CO}_{2}}{\dot{\mathrm{V}}_{\mathrm{A}}} \cdot \mathrm{PB}
$$

Assuming that carbon dioxide production $\left(\dot{\mathrm{V}} \mathrm{CO}_{2}\right)$ is constant,

$$
\mathrm{PB} \times \dot{\mathrm{VCO}_{2}}=\mathrm{Pa}_{\mathrm{CO}_{2}} \times \dot{\mathrm{V}} \mathrm{A}(\text { Equation 1) }
$$

also

$$
\mathrm{Pa}_{\mathrm{CO}_{2}} \propto \dot{\mathrm{V}}_{\mathrm{A}}
$$

Let us now examine minute alveolar ventilation $\left(\dot{\mathrm{V}}_{\mathrm{A}}\right)$

$$
\dot{\mathrm{V}}_{\mathrm{A}}=\dot{\mathrm{V}}_{\mathrm{E}}-\dot{\mathrm{V}}_{\mathrm{D}}
$$


Since $\dot{V}_{E}=V \cdot f$ and $\dot{V}_{D}=V D \cdot f$

$$
\dot{V}_{A}=(V T-V D) \cdot f \quad \text { (Equation 2) }
$$

$\dot{V}_{E}$ is minute ventilation $(\mathrm{ml} / \mathrm{min})$

$\dot{V}_{D}$ is minute dead space $(\mathrm{ml} / \mathrm{min})$

$V T$ is equal to tidal volume $(\mathrm{ml})$

$\mathrm{f}$ is respiratory frequency (breaths $/ \mathrm{min}$ ) $V_{D}$ is tidal dead space $(\mathrm{ml})$

If $\mathrm{VT}$ remains constant, then $(\mathrm{VD} / \mathrm{VT})=\mathrm{K}$ (constant)

$$
\mathrm{VD}=\mathrm{KVT}
$$

Substituting VD $=K V$ in Equation 2

$$
\begin{aligned}
& \dot{V}_{A}=(V T-K V T) \cdot f \\
& \therefore \dot{V}_{A}=(1-K) \cdot V_{T} \cdot f
\end{aligned}
$$

Since $V_{T} \cdot f=\dot{V}_{E}$

$$
\left.\therefore \dot{V}_{A}=(1-K) \dot{V} E \quad \text { (Equation } 3\right)
$$

where $K=V_{D} / V_{T}$

By substituting Equation 3 in Equation 1,

$$
\mathrm{PB} \times \dot{\mathrm{V}} \mathrm{CO}_{2}=\mathrm{Pa}_{\mathrm{CO}_{2}} \times \dot{\mathrm{VE}} \cdot(1-\mathrm{K})
$$

If we again assume a steady state where carbon dioxide production is constant, then the product of any minute ventilation and the resulting $\mathrm{Pa}_{\mathrm{CO}_{2}}$ will be a constant; that is, $\mathrm{PB} \cdot \dot{\mathrm{V}} \mathrm{CO}_{2}=\left(\mathrm{Pa}_{\mathrm{Ca}_{2}}\right)_{1}$. $\left(\dot{\mathrm{V}}_{1}\right)_{1} \cdot(1-\mathrm{K})=\left(\mathrm{Pa}_{\mathrm{CO}_{2}}\right)_{2} \cdot\left(\dot{\mathrm{V}}_{\mathrm{A}}\right)_{2} \cdot(1-\mathrm{K})$. Cancelling $1-\mathrm{K},\left(\mathrm{Pa}_{\mathrm{CO}_{2}}\right)_{1} \cdot\left(\mathrm{VE}_{1}=\left(\mathrm{Pa}_{\mathrm{CO}_{2}}\right)_{2}\right.$. $(\mathrm{VE})_{2}$ where the subscripts represent different minute ventilations and the resulting $\mathrm{Pa}_{\mathrm{CO}_{2}}$.

Therefore, if one knows the arterial carbon dioxide tension and the minute ventilation required to produce this $\mathrm{Pa}_{\mathrm{CO}_{2}}$, then the minute ventilation required to produce a desired $\mathrm{Pa}_{\mathrm{CO}_{2}}$ is shown as:

$$
(\dot{\mathrm{VE}})_{2}=\frac{\left(\mathrm{Pa}_{\mathrm{CO}_{2}}\right)_{1} \cdot(\dot{\mathrm{V}} \mathrm{E})_{1}}{\left(\mathrm{~Pa}_{\mathrm{CO}_{2}}\right)_{2}}
$$

or

$$
\begin{aligned}
& \text { required minute ventilation }= \\
& \text { known } \mathrm{Pa}_{\mathrm{CO}_{2}} \cdot \text { known } \dot{\mathrm{VE}} \\
& \text { desired } \mathrm{Pa}_{\mathrm{CO}_{2}}
\end{aligned}
$$

There are, of course, three clinical requirements for this formula to work.

1. The patient must be in a steady metabolic state, when carbon dioxide production is constant.

2. The dead space/tidal volume ratio must remain unchanged; therefore, changes in minute ventilation should be accomplished by changing the respiratory rate, not the tidal volume. ${ }^{4}$

3. The patient must accept the new minute ventilation without attempting to over-ride the ventilator.

What then are the practical chances that all of these requirements would be satisfied in a general intensive care unit with multiple problems and different types of ventilators? To test this formula, 50 patients with different diagnoses (Table I) were studied using four different types of ventilators (Table II).

\section{Method of Evaluation}

Using the derived formula, changes were made in the minute ventilation for each patient and the predicted $\mathrm{Pa}_{\mathrm{CO}_{2}}$ was compared with the actual $\mathrm{Pa}_{\mathrm{CO}_{2}}$. The blood gas measurements were made after thirty minutes of ventilation at any given minute volume setting. Patients studied appeared metabolically stable and the actual bicarbonate was recorded as a rough measure of metabolic stability. All patients studied were also controlled at the desired minute ventilation.

\section{RESULTS}

Figure 1 compares the measured $\mathrm{PaCO}_{2}$ with the predicted $\mathrm{Pa}_{\mathrm{CO}_{2}}$. It can be seen that the results are highly significant with an $R$ value of 0.973 . The mean difference between observed and predicted $\mathrm{Pa}_{\mathrm{CO}_{2}}$ was $0.153 \mathrm{kPa}(1.1$ torr) \pm S.E.M. $0.106 \mathrm{kPa}$ ( 0.8 torr). The significance of these results appears even greater in view of the fact that the

\section{TABLE I}

PATIENTS STUDIED

\begin{tabular}{lr}
\hline \hline Post Cardiac Surgery & 13 \\
Post Abdominal Surgery & 6 \\
Neurosurgical & 13 \\
Cardiorespiratory Arrests & 4 \\
Pancreatitis & 3 \\
Status Epilepticus & 2 \\
Chest Trauma & 2 \\
GI Bleed & 2 \\
Respiratory Failure with Infiltrates & 4 \\
Septic Shock & 1 \\
$\quad$ Total & 50 \\
\hline
\end{tabular}

TABLE II

VENTILATORS

\begin{tabular}{lr}
\hline \hline Bird & 29 \\
Engstrom & 8 \\
Bennett MA & 7 \\
Ohio CCV & 6 \\
$\quad$ Total & 50 \\
\hline
\end{tabular}




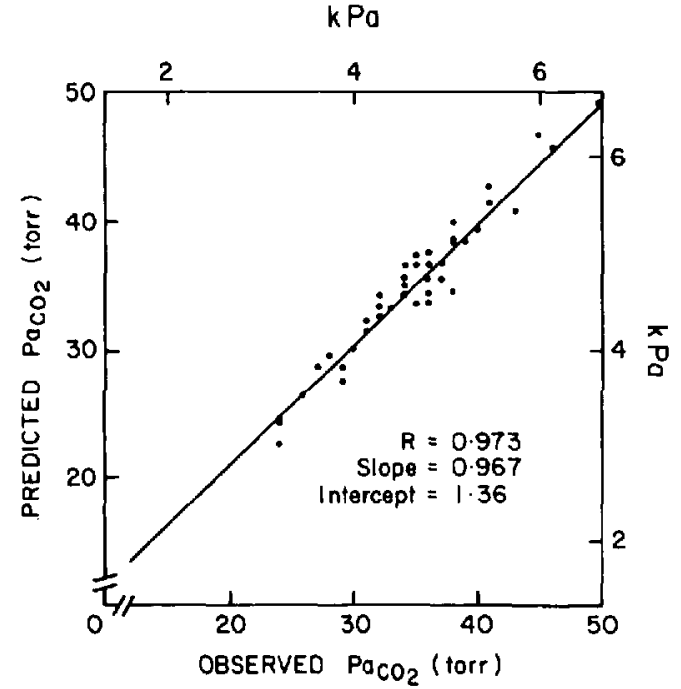

Figure 1 Measured arterial $\mathrm{PCO}_{2}$ on the $\mathrm{x}$-axis is compared with predicted value of arterial $\mathrm{PCO}_{2}$ on the $\mathrm{Y}$-axis. The correlation $(\mathrm{R}=0.973)$ is excellent.

error of $\mathrm{Pa}_{\mathrm{CO}_{2}}$ measurements in our laboratory is $0.133 \mathrm{kPa}$ (1.0torr). There was no significant change in the measurement of bicarbonate in the patients studied, nor was there any difference in subgroups of diagnosis or ventilator type.

\section{- Discussion}

We feel that after an initial blood gas determination and measurement of the patient's minute ventilation we can now more accurately adjust the arterial $\mathrm{PCO}_{2}$ and the patient's acid base balance by the use of this formula. This reduces the number of changes in minute ventilation and repeated blood gas analyses. The limitations of the formula and its application must be recognized. The patient should be in a stable metabolic state with reasonably constant carbon dioxide production. If the paticnt is agitated or is triggering the ventilator at a rate different from that desired, obviously the formula will not work.

Once a desired tidal volume has been selected for the patient, it should be maintained and changes in minute ventilation should be made by varying respiratory frequency. While Nunn 5 states that equilibration time for arterial $\mathrm{PCO}_{2}$ is longer with a drop in minute ventilation than with a rise in minute ventilation, this was not evident in our results and the predictive value of the formula was no different for increases or decreases in minute ventilation. Therefore it appears that after thirty minutes of steady ventilation the adjustment by excretion or retention of carbon dioxide has stabilized and an accurate measure of arterial $\mathrm{PCO}_{2}$ can be obtained approximately thirty minutes after a change of minute ventilation.

\section{REFERENCES}

1. RADFORD, E.P. Ventilation standards for use in artificial respiration. J. Appl. Physiol. 7: 451 (1955).

2. Nunn, J.F. Applied Respiratory Physiology, 2nd Edition. London: Butterworths (1977).

3. RiLey, R.L. \& Cournand, A. Analysis of factors affecting partial pressures of oxygen and carbon dioxide in gas and blood of lungs. J. Appl. Physiol. 1: $825(1951)$.

4. WATSON, W.E. Observations on physiological dead space during intermittent positive pressure respiration. Br. J. Anaesth. 34: 502 (1962).

5. Nunn, J.F. Applied Respiratory Physiology, 2nd Edition, London: Butterworths (1977).

\section{RÉSUMÉ}

Pour améliorer la précision du réglage de l'équilibre acido-basique chez les malades sous ventilation mécanique nous vaons déduit la formule:

$$
\text { Ventilation minute requise }=\frac{\mathrm{PCO}_{2} \text { artériel connu } \times \text { ventilation minute connue }}{\mathrm{PCO}_{2} \text { artériel désiré }}
$$

ce qui permet de calculer la ventilation minute requise pour produire un niveau de $\mathrm{PCO}_{2}$ artériel désiré en mesurant la $\mathrm{PCO}_{2}$ artérielle actuelle du patient et sa ventilation minute. Cette formule a été vérifiée sur 50 patients lors de l'emploi de quatre types de ventilateurs et nous l'avons trouvée statistiquement précise avec une différence moyenne entre la $\mathrm{PCO}_{2}$ prédite et observée de $0.153 \mathrm{kPa}(1.15$ torr) + S.E.M. 0.798. 